Kavruk, H. ve Çeçen, M.A. (2013). Türkçe dersi yazılı sınav sorularının bilişsel alan basamakları açısından değerlendirilmesi. Ana Dili Eğitimi Dergisi, 1(4), 1-9.

Ana Dili Eğitimi Dergisi
Journal of Mother Tongue Education
ADED - JOMTE
www.anadiliegitimi.com

\title{
Türkçe Dersi Yazılı Sınav Sorularının Bilişsel Alan Basamakları Açısından \\ Değerlendirilmesi
}

Hasan KAVRUK*

Mehmet Akif ÇEÇEN ${ }^{* *}$

\begin{abstract}
Özet
Bu araştırmanın amacı Türkçe öğretmenlerinin ölçme değerlendirme amacıyla yaptığı yazılı sınav sorularının hangi seviyede becerileri ölçtüğünü Bloom taksonomisine göre tespit etmektir. Araştırmada Malatya il merkezinde bulunan 12 ilköğretim okulunda görev yapan 38 Türkçe öğretmeninin 6, 7 ve 8. sınıf derslerinde yaptıkları yazılı sınavlar incelenmiş, bu sınavlarda sorulan 2427 soru, araştırma kapsamında değerlendirilmiştir. Araştırma sonucunda soruların büyük kısmının alt düzey becerileri ölçen bilgi, kavrama ve uygulama basamağında olduğu görülmüştür. Sınıf seviyesine göre soruların basamaklarında düzenli bir yükselişin görülmediği araştırmada ulaşılan sonuçlardan biri de okullar arasında düzenli bir dağılımın olmayışıdır.
\end{abstract}

Anahtar kelimeler: Bloom taksonomisi, Türkçe öğretimi, ölçme-değerlendirme

Evaluation of Turkish Language Class Exam Questions in Point of Cognitive Field Levels

\begin{abstract}
The aim of this study is to determine level skills of exam questions that prepared by Turkish language teachers' in point of Bloom taxonomy. In the research 38 Turkish language teachers' written exams of 6, 7 and $8^{\text {th }}$ classes in 12 primary schools in Malatya were studied. In this case 2427 questions were examined. As a result it was seen that most of questions are in knowledge, insight and application levels. There is no rising through grades in point of taxonomy and also no regular distribution in grades.
\end{abstract}

Key words: Bloom taxonomy, Turkish language teaching, assessment and evaluation

\section{Giriş}

Eğitimin amacı, öğrenme ve gelişme istidadıyla dünyaya gelen insanın, ideal, üstün niteliklere sahip olmasını sağlamak, bunun için gerekli faaliyetleri, çalışmaları planlamaktır. Eğitimin gerçekleşmesi adına yapılacak etkinlikler, insanın yaşı gibi bazı özelliklerine göre belirlenir. Somut ve

\footnotetext{
* Prof. Dr., İnönü Üniversitesi Eğitim Fakültesi Türkçe Eğitimi Bölümü, Malatya. E-posta: hasan.kavruk@inonu.edu.tr

${ }^{* *}$ Doç. Dr., İnönü Üniversitesi Eğitim Fakültesi Türkçe Eğitimi Bölümü, Malatya. E-posta: mehmet.cecen@inonu.edu.tr
} 
soyut kavramların; bilişsel, duyuşsal ya da psiko-motor nitelikteki becerilerin kazandırılmasında yaş, cinsiyet, ilgi ve ihtiyaç gibi özellikler, şartlar dikkate alınır.

Günümüzde eğitimin temelinde yer alan yapılandırıcı yaklaşımda öğrenme, bireyin aktif çabalarıyla oluşmakta ve zihninde yapılandırılmaktadır. Öğrenciyi ve öğrencinin zihnini merkeze alan bu yaklaşımda öğretimden çok öğrenme üzerinde durulmaktadır. Beyin araştırmalarına ve yapılandırııı yaklaşıma göre dilin öğrenilmesi tamamen zihinsel işlemlere dayalı olarak gerçekleşmektedir (Güneş, 2007: 32). Bu yüzden eğitimin bütün aşamaları, yapılandırmacı yaklaşım ekseninde planlanmalıdır.

Ölçme değerlendirme yapmak amacıyla yapılan sınavlarda sorulan sorular, öğrencinin zihnini etkileyeceğinden zihinsel yapılandırmada önemli bir role sahiptir. Ölçülmek istenen düzeye göre soru, öğrencinin düşünme becerisinin de düzeyini belirler. Bilişsel alanın alt düzeylerinde yer alan soruların katkıda bulunacağı zihinsel yapılandırmayla üst düzey sorularınki arasında bazı farkların olması doğaldır.

Öğretmenin öğrencilere sorular sormasının faydası ve bu soruları sorarken izleyeceği yöntemler belli olmasına rağmen araştırmalar öğretmenlerin sordukları soruların niteliği hakkında iyimser sonuçlar vermemektedir. Yapılan çalışmalar, öğretmenlerin sorduğu soruların yaklaşık olarak \%85'inin olgularla ilgili ve hatırlamaya dönük sorular olduğunu ortaya koymaktadır (Aktaran: Ensar, 2002). Oysa "amaçlı olarak sorulan bilgi ve kavrama düzeyi sorularının öğrenciyi daha üst düşünme düzeyine doğru yönelttiği de yapılan araştırma bulgularındandır." (Özbay, 2002).

Türkçe dersi öğretim programının genel amaçları içerisinde yer alan "Anlama, sıralama, ilişki kurma, sınıflama, sorgulama, eleştirme, tahmin etme, analiz-sentez yapma, yorumlama ve değerlendirme becerilerini geliştirme" (MEB, 2006) maddesinden Programın öğrencilere üst düzey düşünme becerilerini kazandırmak istediği anlaşılmaktadır. Öğretmenler, bu becerilerin öğrenciye kazandırılıp kazandırılamadığını ancak ölçme değerlendirme etkinlikleriyle belirleyebilir.

Alternatif ölçme değerlendirme yollarının dışında uygulanan ölçme değerlendirme çalışmaları, Türkçe derslerinde yazılı sınavlarla olmaktadır. Bu sebeple öğretmenlerin öğrencilere sorduğu soruların, üst düzey becerileri de ölçebilecek nitelikte olması beklenmektedir. Bilişsel becerileri ölçebilecek soruların sınıflandırılması, her bir sorunun öğrencinin hangi bilişsel düzeyde olduğunun tespit edilmesi için en çok kullanılan tasnif Bloom Taksonomisi'dir.

Bloom Taksonomisi, bilgi, kavrama, uygulama, analiz, sentez ve değerlendirme basamaklarından oluşmaktadır. Bloom ve arkadaşları tarafından geliştirilen sınıflandırmaya göre alt düzey düşünme becerileri bilgi, kavrama ve uygulama, üst düzey düşünme becerileri ise analiz, sentez ve değerlendirme basamaklarını ifade etmektedir (Şahinel, 2002). Taksonominin gözden geçirilmiş 
hâlinde ise sentez ve değerlendirme basamakları yer değiştirmiş; sentez, bilişsel alanın en üst basamağında kabul edilmiştir (Arı, 2011).

Sentez basamağı, özgünlüğü, yeni bir ürün ortaya koymayı ifade ettiği için “değerlendirme"ye göre daha üst düzeyde bir beceriye karşılık gelmektedir. Bu bakımdan gözden geçirilmiş taksonomideki bu değişikliğin yerinde olduğu söylenebilir.

“Öğretim sonunda öğrencilerden beklenen durumların sınıflandırılmasına imkân veren bir iskelet olarak tanımlanan taksonomi, orijinal hâlinde aşamalı bir sınıflamadır. Buna göre taksonomideki basamaklar, basitten karmaşığa, somuttan soyuta doğru bir sıra izlemekte ve her bir basit basamak, daha karmaşık bir diğer basamak için ön koşul olma özelliği taşımaktadır." (Bümen, 2006: 4).

“Bloom Taksonomisi, her ne kadar eğitim öğretim hedeflerinin sınıflamasına yönelik olsa da gerek öğretmenler gerekse araştırmacılar tarafından özellikle bilişsel alandaki soru seviyelerinin belirlenmesinde de kullanılmaktadır." (Dindar ve Demir, 2006: 90).

Öğretmenler, bilgilerin ezberlenmesini sağlamaktansa öğrencinin düşünmesine ve eleştirmesine, karar vermesine ve problem çözmesine yardımcı olacak sorular sormalıdır. Üst düzey sorular (sentez, değerlendirme, analiz gibi), öğrencilere fikirleri hatırlatmak yerine onları kullanmalarında yardımcı olur (Ensar, 2002). Bu sebeple öğretmenler, sordukları soruları düşünme becerilerinin düzeyine göre sınıflandırmalı ve -özellikle sınıf seviyesi ilerledikçe- üst düzey düşünme becerilerini geliştirecek sorulara yer vermelidir.

Anlama ve anlatma olmak üzere iki temel alana ayrılan dil becerilerinden oluşan Türkçe derslerinde bilgilerin yapılandırılması kadar metinleri anlamada da soruların önemli bir işlevi vardır. Illköğretim 2. kademe (6, 7 ve 8. sınıf) Türkçe öğretmenlerinin yazılı sınavlarda kullandıkları sorularla ilgili benzer çalışmalar (Güfta ve Zorbaz, 2008; Şen ve Beyaztaş, 2008) var ise de bunların gerek örneklemi gerekse zamanı farklıdır. O yüzden bu çalışmanın ilgili alana katkı sağlayacağı düşünülmektedir.

Bu araştırmanın amacı, Türkçe öğretmenlerinin yazılı sınavlarda sorduğu soruların, bilişsel alan basamaklarına göre nasıl bir dağılım gösterdiğini, soruların yer aldığı basamakların sınıf seviyesine göre değişip değişmediğini belirlemektir.

\section{YÖNTEM}

\section{Araştırmanın Modeli}

Öğretmenlerin hazırladığı ölçme ve değerlendirme sorularını Bloom Taksonomisine göre incelemeyi amaçlayan bu çalışma betimsel tarama modeli niteliğindedir. 
Araştırmada doküman incelemesi yöntemi kullanılmıştır. Doküman incelemesi, araştırıması hedeflenen olgu ve olgular hakkında bilgi içeren yazılı ve görsel materyallerin incelenmesidir (Yıldırım ve Şimşek, 2006).

\section{Örneklem}

Araştırma grubunu, 2008-2009 eğitim ve öğretim yılında Malatya merkezde ulaşım imkânları göz önünde bulundurularak seçilmiş 12 ilköğretim okulundaki Türkçe öğretmenleri tarafından hazırlanan yazılı sınav soruları oluşturmaktadır. Araştırma yapılan okulların isimleri alfabetik olarak sıralanıp numaralandırılmıştır. Soruları hazırlayan öğretmenlerin okullara göre dağılımı şöyledir:

Tablo 1. Okullara Göre Öğretmen Sayıları

\begin{tabular}{ll}
\hline Okullar & Öğretmen SayısI \\
\hline I & 2 \\
II & 4 \\
III & 4 \\
IV & 4 \\
V & 3 \\
VI & 2 \\
VII & 4 \\
VIII & 3 \\
IX & 5 \\
X & 2 \\
XI & 2 \\
XII & 3 \\
\hline Toplam & $\mathbf{3 8}$ \\
\hline
\end{tabular}

\section{Verilerin Toplanması}

Türkçe öğretmenleri tarafından sorulan sınav soruları, araştırma grubundaki 12 okulun Türkçe öğretmenlerinden elde edilmiştir. Türkçe öğretmenlerinin 2008-2009 eğitim-öğretim yılında altı, yedi ve sekizinci sınıf Türkçe dersi sınavları için hazırlamış oldukları sınav kâğıtlarında yer alan soruların ölçtüğü bilişsel düzeyler; soruların Bloom Taksonomisi'ne göre sınıflandırılmaları doğrultusunda tespit edilmiştir. Araştırma grubundaki öğretmenlerin hazırladığı altıncı sınıf düzeyinde 52 kâğıttaki 717, yedinci sınıf düzeyinde 56 kâğıttaki 864 ve sekizinci sınıf düzeyinde 60 sınav kâğıdındaki 846 soru incelenmiştir.

\section{Verilerin Analizi}

Ölçme ve değerlendirme amacıyla kullanılacak yazılı kâğıtlarındaki sorular, Bloom Taksonomisi'ne göre yüzde ve frekans hesaplamaları kullanılarak sınıflandırılmıştır. 


\section{Bulgular ve Yorumlar}

Sınav sorularının bilişsel alan basamaklarına dağılımının sınıf düzeylerine göre nasıl olduğuna ilişkin bulgular Tablo 2'de yer almaktadır:

Tablo 2. 6, 7 ve 8. Sınıf Türkçe Sorularının Sınıflara Dağııımı

\begin{tabular}{lcccccccc}
\hline \multirow{2}{*}{ Bilişsel Basamaklar } & \multicolumn{2}{c}{ 6. Sınıf } & \multicolumn{2}{c}{ 7. Sınıf } & \multicolumn{2}{c}{ 8. Sınıf } & \multicolumn{2}{c}{ Toplam } \\
\cline { 2 - 9 } Bilgi & $\mathbf{f}$ & $\mathbf{\%}$ & $\mathbf{f}$ & $\mathbf{\%}$ & $\mathbf{f}$ & $\mathbf{\%}$ & $\mathbf{f}$ & \% \\
\cline { 2 - 9 } Kavrama & 228 & 34,7 & 216 & 32,9 & 213 & 32,4 & 657 & 100 \\
Uygulama & 262 & 28,3 & 338 & 36,5 & 326 & 35,2 & 926 & 100 \\
Analiz & 128 & 29,6 & 163 & 37,7 & 141 & 32,7 & 432 & 100 \\
Sentez & 55 & 22,2 & 90 & 36,3 & 103 & 41,5 & 248 & 100 \\
Değerlendirme & 44 & 29,8 & 52 & 35,1 & 52 & 35,1 & 148 & 100 \\
\hline
\end{tabular}

Tablo 2'de soruların bilişsel basamaklara göre dağılımı, sınıflar seviyesinde incelenmiştir. Bilgi basamağındaki sorular, üç sınıf seviyesinde birbirine yakın $(\% 34,7, \% 32,9, \% 32,4)$ bir dağılım göstermiştir. Kavrama basamağındaki sorular, 6.sınıfta hazırlanan soruların \%28,3'ünü oluştururken 7 ve 8. sınıfta bu oranın arttığı görülmektedir. 7. sınıflar için hazırlanan soruların $\% 36,5^{\prime} \mathrm{i}, 8$. sınıflar için hazırlanan soruların da \%35,2'si bu basamaktadır. Uygulama basamağında da kavrama basamağına benzer bir dağılım vardır (6. sınıfta \%29,6; 7.sınıfta \%37,7; 8. sınıfta \%32,7). Kavrama ve uygulama basamağındaki sorular alt düzey düşünme becerilerini geliştiren sorular olduğu için bu sorulara 6 . sınıfta daha az yer verilmesi olumlu bir durum olarak değerlendirilebilir. Analiz ve sentez basamaklarındaki sorulara en çok 8. sınıfta, en az da 6. sınıf seviyesinde yer verildiği görülmektedir. Değerlendirme basamağındaki sorulara en çok 8. sınıfta yer verilirken en az 7. sınıf seviyesinde yer verilmiştir. Üst düzey düşünme becerisini geliştirmek için hazırlanan analiz, sentez ve değerlendirme basamakları sorularının en çok 8. sınıf seviyesinde kullanılıyor olması yaş ve düşünme becerileri arasındaki ilişkinin göstergesi olarak yorumlanabilir.

Soruların sınıflar düzeyinde bilişsel alan basamaklarına dağılımına ilişkin bulgular Tablo 2'de yer almaktadır:

Tablo 3. 6, 7 ve 8. Sınıf Türkçe Sorularının Bilişsel Basamaklara Dağıımı

\begin{tabular}{|c|c|c|c|c|c|c|c|c|}
\hline Sinıf & & Bil. & Kav. & Uyg. & Ana. & Sen. & Değ. & Toplam \\
\hline \multirow{2}{*}{6} & $f$ & 228 & 262 & 128 & 55 & 44 & 12 & 729 \\
\hline & $\%$ & 31,3 & 35,9 & 17,6 & 7,5 & 6,0 & 1,7 & 100 \\
\hline \multirow{2}{*}{7} & $f$ & 216 & 338 & 163 & 90 & 52 & 7 & 866 \\
\hline & $\%$ & 25,0 & 39,0 & 18,8 & 10,4 & 6,0 & 0,8 & 100 \\
\hline \multirow{2}{*}{8} & $f$ & 213 & 326 & 141 & 103 & 52 & 13 & 848 \\
\hline & 12 & 25,1 & 38,5 & 16,6 & 12,2 & 6,1 & 1,5 & 100 \\
\hline
\end{tabular}


Altıncı sınıf düzeyindeki soruların yaklaşık \%85'i bilgi, kavrama ve uygulama basamağında yer alırken $\% 15^{\prime} i$ üst düzey düşünme becerilerini ifade eden analiz, sentez ve değerlendirme basamağındadır. Bu oran, yedinci sınıfta yaklaşık olarak \%83'e \%17; sekizinci sınıfta \%80'e \%20'dir. Sınıf seviyesi yükseldikçe üst düzey düşünme becerilerini ölçen soru sayısındaki artış olumlu görünmektedir. Ancak üst düzey soruların oranının tüm sorulara oranının, sekizinci sınıfta bile $1 / 5$ seviyesinde olması, üzerinde durulması gereken bir husustur.

Çalışkan (2011) tarafından yapılan araştırmada 2008-2009 öğretim yılındaki Sosyal Bilgiler dersi 6. sınıf sorularının yaklaşık olarak \%74'ü bilgi, kavrama ve uygulama basamağında; \%26'sı da analiz, sentez ve değerlendirme basamağındadır. Basamaklar arasındaki oran 7. sınıfta \%73'e \%27'dir. Bu araştırmadaki bulgularla karşılaştırıldığında Sosyal Bilgiler dersi sınav sorularında üst düzey düşünme becerilerini ölçen soruların -araştırmanın yapıldığı örneklem düzleminde- nispeten daha fazla olduğu görülmektedir.

Beşinci sınıf Fen Bilgisi dersinde sorulan soruları Bloom taksonomisine göre inceleyen Dindar ve Demir (2006) soruların \%99'una yakınının ilk üç basamakta yer aldığını, geriye kalan \%1'i geçen bir kısmının analiz ve sentez basamağında olduğunu ve değerlendirme basamağında hiç soru bulunmadığını belirlemiştir.

Türkçe dersi sınav sorularının ölçtüğü bilişsel alan basamaklarının okullara dağılımına ilişkin bulgular, Tablo 4'te yer almaktadır:

Tablo 3. Soruların Ölçtüğü Bilişsel Basamakların Okullara Göre Dağılımı

\begin{tabular}{|c|c|c|c|c|c|c|c|}
\hline Okullar & Bilgi & Kavrama & Uygulama & Analiz & Sentez & Değerlendirme & Toplam \\
\hline I & 17 & 34 & 46 & 16 & 3 & 4 & 120 \\
\hline II & 28 & 51 & 14 & 14 & 4 & - & 111 \\
\hline III & 170 & 183 & 54 & 25 & 16 & 5 & 453 \\
\hline IV & 36 & 115 & 53 & 46 & 14 & - & 264 \\
\hline V & 64 & 54 & 19 & 21 & 15 & 2 & 175 \\
\hline VI & 17 & 23 & 28 & 3 & 11 & - & 82 \\
\hline VII & 151 & 299 & 86 & 39 & 25 & 10 & 610 \\
\hline VIII & 10 & 29 & 22 & 24 & 7 & 1 & 93 \\
\hline IX & 21 & 39 & 56 & 23 & 12 & 5 & 156 \\
\hline$x$ & 85 & 48 & 20 & 10 & 15 & - & 178 \\
\hline $\mathbf{X I}$ & 24 & 26 & 23 & 17 & 11 & 2 & 103 \\
\hline XII & 34 & 25 & 11 & 10 & 15 & 3 & 98 \\
\hline Toplam & 657 & 926 & 432 & 248 & 148 & 32 & 2443 \\
\hline
\end{tabular}

Tablo 4'te hazırlanan sınav sorularına, basamaklara göre en fazla ve en az yer veren okullar şu şekilde tespit edilmiştir:

Hazırlanan sorularda bilgi basamağına \%47,76 ile X; kavrama basamağına \%49,02 ile VII; uygulama basamağına \%35,90 ile IX; analiz basamağına \%25,8 ile VIII; sentez basamağına \%15,31 ile XII ve değerlendirme basamağına \%3,33 ile I numaralı okul en fazla yer vermiştir. 
Hazırlanan sorularda bilgi basamağına \%10.76 ile VIII, kavrama basamağına \%25 ile IX, uygulama basamağına \%10.85 ile $\mathrm{V}$, analiz basamağına \%3.66 ile $\mathrm{VI}$, sentez basamağına \%2.5 ile I, değerlendirme basamağına da \%1.08 ile VIII numaralı okullar en az oranda yer vermiştir. X, IV, II ve VI numaralı okullar ise değerlendirme basamağındaki sorulara hiç yer vermemiştir.

Okulların tümünde soruların basamaklara dağııımına ilişkin yüzde oranları Şekil 1'de gösterilmiştir:

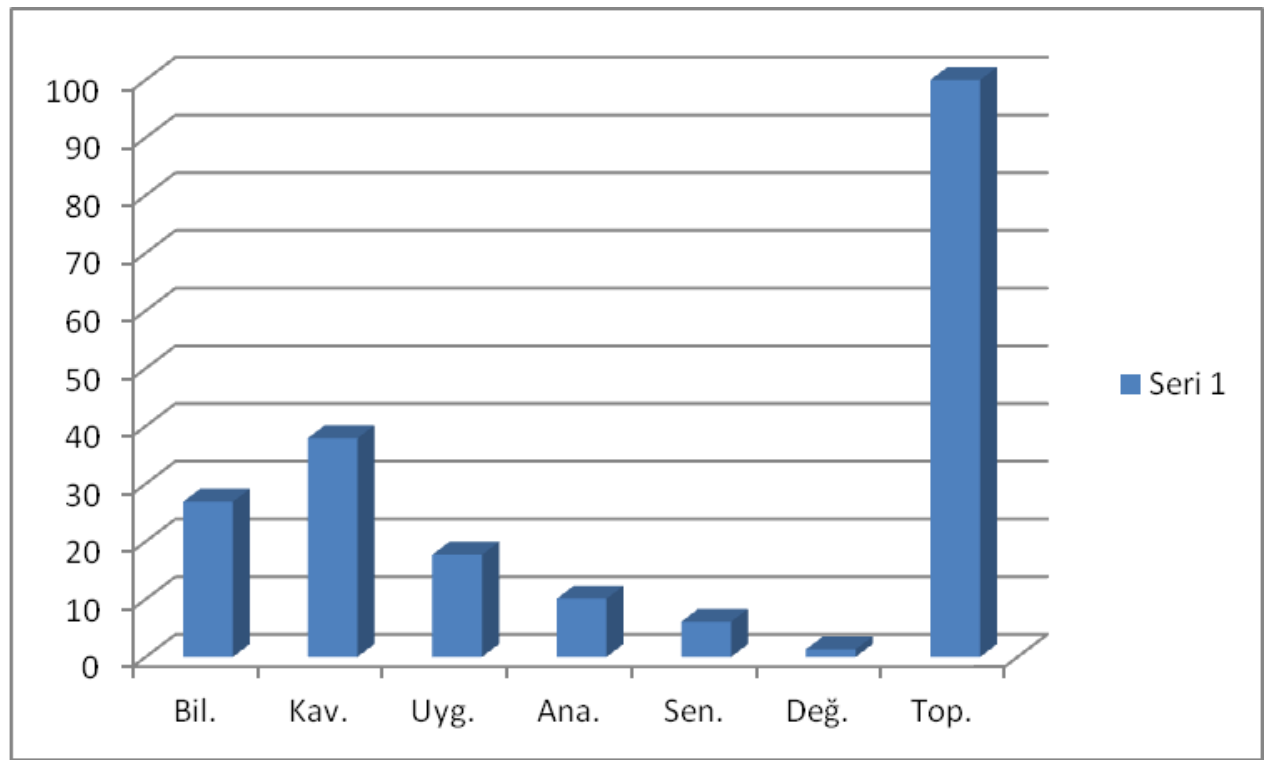

Şekil 1. Soruların basamaklara dağılımına iliş̧in yüzde oranları

Şekil1'de, hazırlanan soruların bütününe bakıldığında incelenen soruların, en çok kavrama düzeyindeki (\%38) becerileri ölçtüğü görülmektedir. Bilgi düzeyindeki (\%27) sorulara da oldukça yoğun bir şekilde yer verilmiştir. Bloom Taksonomisi'nin üst düzey düşünme becerilerini kapsayan basamaklarına doğru gidildikçe öğretmenlerin bu basamaklarla ilgili hazırladığı soruların oranında [uygulama (\%18), analiz (\%10), sentez (\%6)] azalma olduğu tespit edilmiştir. En üst düzey düşünme becerisini ifade eden değerlendirme basamağındaki soruların (\%1) ise en az sorulan sorular olduğu görülmektedir. Bu durum, hazırlanan yazılı sınavlardaki soruların, üst düzey düşünme becerilerini ölçmek için yeterli olmadığı şeklinde değerlendirilebilir.

\section{Tartışma ve Sonuç}

Araştırmanın sonucunda 2008-2009 eğitim-öğretim yılında Türkçe öğretmenlerinin yaptıkları sınavlarda kullanılan soruların çoğunluğunu kavrama ve bilgi düzeyindeki soruların oluşturduğu belirlenmiştir. Bu sonuç, Güfta ve Zorbaz (2008) tarafından yapılan araştırmanın sonuçlarıyla örtüşmektedir. Uygulama ve analiz sorularının da yazııı kâğıtlarında yer almasına dikkat edildiği söylenebilir. Kavrama düzeyindeki soruların bilgi düzeyindeki sorulardan daha fazla olması; uygulama ve analiz sorularının da yazılı kâğıtlarında yer alması öğretmenlerin bilgiye dayalı sorular sormaktan 
uzaklaştığı şeklinde yorumlanabilir. Ancak sentez, özellikle de değerlendirme düzeyindeki soruların sınavlarda daha az sorulan sorular olması, öğretmenlerin hâlâ öğrencilere üst düzey beceriler kazandıracak sorular sormadığının bir göstergesi olarak yorumlanabilir.

Soruların ölçtüğü bilişsel basamakların sınıflara göre dağılımı incelendiğinde 6. sınıfta bilgi basamağındaki soruların $(\% 34,7)$, değerlendirme basamağındaki sorulardan $(\% 37,5)$ daha az kullanıldığı görülmektedir. Soruların $\% 37,5^{\prime}$ inin değerlendirme basamağından oluşması 6 . sınıf düzeyinde öğrencilere üst düzey düşünme becerisi kazandıracak soruların sorulduğunu göstermektedir. 7. sınıfta bilgi basamağındaki soruların (\%32,9), değerlendirme basamağındaki sorulardan $(\% 21,9)$ daha fazla kullanıldığı görülmektedir. 6. sınıf düzeyindeki üst düzey beceri kazandırmak amacıyla sorulan soruların; 7. sınıf düzeyinde azalması, öğrencilerin her sınıf düzeyinde artması beklenen üst düzey düşünme becerilerinin gelişimi ile doğru orantılı değildir. 8. sınıfta bilgi basamağındaki soruların $(\% 32,4)$, değerlendirme basamağındaki sorulardan $(\% 40,6)$ az olduğu görülmektedir. 8. sınıfta sorulan değerlendirme basamağındaki soruların, diğer sınıf düzeylerine oranla daha fazla olduğu görülmektedir. Bu durum; öğretmenlerin sorduğu soruların, yaş ile birlikte gelişmesi beklenen üst düzey düşünme becerilerinin kazandırılmasına yönelik olduğu şeklinde değerlendirilebilir.

Her okulda sorulan soruların düzeyinin farklı olması öğretmenlerin öğrencileri aynı bilişsel düzeydeki kazanımlara ulaştıramadığını göstermektedir. Bazı okullarda (X ve V) hâlâ \%50 oranında bilgi düzeyinde sorular sorulduğundan, bu okulların Bloom Taksonomisi'nin en alt düzeyinde kalmış oldukları görülmekte, bazı okullarda (XII ve IX) ise her düzeyden soruya yer verilerek öğrencilerin üst düzey düşünme becerilerini geliştirmeye katkı sağladıkları söylenebilir.

İncelenen okulların birçoğunda öğretmenlerin üst düzey becerilere yer veriyor olması, yeni programa uygun bir şekilde soru sorma becerilerini geliştirdikleri şeklinde yorumlanabilir. Çalışkan (2011), öğretmenler tarafından hazırlanan soruların düzeylerinin gelişmesini, programların yenilenmesinden dolayı öğretmenlere verilen eğitimlerin artmasına, öğretmenlerin kendilerini geliştirme zorunluluğu hissetmelerine ve genel sınavların soru formatına uygun soru hazırlama eğilimlerine bağlamaktadır.

Şen ve Beyaztaş (2008) tarafından yapılan çalışmada sınıf öğretmenlerinin Türkçe dersi sınavlarında en fazla bilgi, kavrama ve uygulama soru düzeylerini kullandıkları; analiz, sentez ve değerlendirme sorularına hiç yer vermedikleri bulgusu elde edilmiştir. Sözü edilen çalışma ile bu araştırma sonucu arasındaki fark, bu araştırmada az da olsa analiz, sentez düzeyinde soruların kullanılması olmuştur. Araştırma grupları farklı olsa da her geçen yılda sorulan soruların düzeyinde bir yükselişin olduğu görülmektedir. 
Öğretmenlerin daha fazla üst düzey beceri kazandıracak sorular sormaları için bilgilendirilmesi, yapılan yazıııların öğretim programına uygun olup olmadığının denetlenmesi, öğretmenleri bilgi, kavrama düzeyi sorularıyla birlikte sentez, değerlendirme sorularına yönlendirebilir. Ayrıca öğretmen yetiştiren kurumların ölçme ve değerlendirme derslerinde öğretmen adaylarına nasıl sorular sorulması gerektiğine dair tüm bilgiler verilmelidir. Öğretmen adaylarının ikinci kademe Türkçe dersi öğretim programındaki amaçlara uygun sorular sorabilecek hâle getirilmesi ve iyi bir sınav kâğıdı hazırlamanın tüm inceliklerinin öğretilmesi de gerekmektedir.

\section{Kaynakça}

Arı, A. (2011). Bloom'un Gözden Geçirilmiş Bilişsel Alan Taksonomisinin Türkiye'de ve Uluslararası Alanda Kabul Görme Durumu, Kuram ve Uygulamada Eğitim Bilimleri, 11 (2), 749-772.

Bümen, N. T. (2006). Program Geliştirmede Bir Dönüm Noktası: Yenilenmiş Bloom Taksonomisi, Eğitim ve Bilim, Cilt 31, Sayı 142, 3-14.

Çalışkan, H. (2011). Öğretmenlerin Hazırladığı Sosyal Bilgiler Dersi Sınav Sorularının Değerlendirilmesi, Eğitim ve Bilim, Cilt 36, Sayı 160, 120-132.

Dindar, H. ve Demir, M. (2006). Beşinci Sınıf Öğretmenlerinin Fen Bilgisi Dersi Sınav Sorularının Bloom Taksonomisine Göre Değerlendirilmesi, GÜ, Gazi Eğitim Fakültesi Dergisi, Cilt 26, Sayı 3, 87-96.

Ensar, F. (2002). ilköğretim 6. Sınıf Türkçe Ders Kitaplarındaki Metin Altı Soruları Üzerine Bir Inceleme. Yayımlanmamış Yüksek Lisans Tezi. Gazi Üniversitesi Eğitim Bilimleri Enstitüsü. Ankara.

Güftâ, H. ve Zorbaz, K. Z. (2008). İlköğretim İkinci Kademe Türkçe Dersi Yazılı Sınav Sorularının Düzeyleri Üzerine Bir Değerlendirme. Çukurova Üniversitesi Sosyal Bilimler Enstitüsü Dergisi, 17(3), 205-218.

Güneş, F. (2007). Türkçe Öğretimi ve Zihinsel Yapılandırma. Ankara: Nobel Yayın Dağııım.

MEB (2006). İlköğretim Türkçe Dersi Öğretim Programı ve Kılavuzu (6, 7, 8. Sınıflar). Ankara: Devlet Kitapları Müdürlüğü.

Özbay, M. (2002). Illköğretim Okulları Türkçe Ders Kitaplarındaki Anlama Sorularının Öğrencilerin Düşünme Becerilerine Katkısı, Türk Dili Dergisi, S. 609, 536-546.

Şahinel, S. (2002), Eleştirel Düşünme, Pegem A Yayıncılık, Ankara

Sen, S. ve Beyaztaş, D. I. (2008), Beşinci Sınıf Öğretmenlerinin Türkçe Dersi Sınav Sorularının Bloom Taksonomisi'ne Göre Değerlendirilmesi, Erzincan Üniversitesi Sosyal Bilimler Enstitüsü Dergisi, 1 (1), 67-83

Yıldırım, A. ve Şimşek, H. (2006). Sosyal Bilimlerde Nitel Araştırma Yöntemleri (5. Baskı). Ankara: Seçkin Yayıncılık. 